\title{
Estudo sobre eficácia da aplicação de um objeto de aprendizagem com alunos do ensino fundamental
}

Dariel de Carvalho prof.darielcarvalho@gmail.com 0000-0003-4957-0058 Doutor em Educação

Clerison José de Souza Bueno clerisonbueno@gmail.com 0000-0002-9619-4174 Universidade Estadual Paulista UNESP/Bauru

Ketilin Mayra Pedro ketilinp@yahoo.com.br 0000-0002-1893-5002 Universidade do Sagrado Coração USC/Bauru

Elvio Gilberto da Silva egilberto@uol.com.br

0000-0001-7346-5341

Universidade do Sagrado Coração USC/Bauru

\section{RESUMO}

Este estudo teve por objetivo verificar a eficácia de um objeto de aprendizagem de geografia, na aplicação com alunos do ensino fundamental. Para isso, foi construído um objeto de aprendizagem com o título Regiões do Brasil, o qual foi aplicado em 25 alunos do $5^{\circ}$ ano do ensino fundamental. Foi realizada uma avaliação inicial, com o intuito de analisar o conhecimento dos alunos sobre o tema abordado e, de acordo com os resultados, os alunos foram separados em dois grupos homogêneos, grupo-controle e experimental. Foi feita a aplicação do objeto no laboratório de informática para o grupo experimental, enquanto o grupo-controle efetuava atividades sobre o assunto com o professor em sala de aula. Após a intervenção, os grupos realizaram avaliação final. Os resultados mostraram uma diferença de apenas quatro por cento entre os grupos. Pode-se concluir a eficácia do recurso criado e a sua importância no processo de ensino-aprendizagem.

PALAVRAS-CHAVE: Objeto de aprendizagem. Geografia. Ensino. 


\section{INTRODUÇÃO}

As tecnologias digitais estão cada vez mais presentes na sociedade atual, por meio dos avanços contínuos e da evolução dos computadores, que a cada dia ficam mais baratos e mais comuns a todos, principalmente aos alunos.

Os jovens que fazem parte dessa nova geração rapidamente associam as novas tecnologias ao seu contexto e as utilizam constantemente, principalmente para a troca de informação rápida. Segundo Santaella (2004), os jovens buscam interatividade instantânea, quando interagem com os recursos tecnológicos.

Com essa tecnologia mais presente, surgem diversos recursos que podem ser explorados através dos computadores, e esse fato não pode passar despercebido, pois os alunos estão esperando encontrar na escola um local no qual possam interagir, assim como fazem quando estão fora dela.

Dessa maneira, Suzuki e Rampazzo (2009) e Vickery (2016) argumentam que a escola tem o papel da formação do indivíduo e deve disponibilizar o contato dos alunos com as novas tecnologias e, além disso, torná-las favoráveis para o crescimento da aprendizagem, através da incorporação de práticas diárias dessa tecnologia.

Uma das formas de poder usar as tecnologias dentro das práticas docentes é através da utilização de um objeto de aprendizagem, que, segundo Wiley (2000, p. 3 ), pode ser entendido como "qualquer recurso digital que possa ser reutilizado para o suporte ao ensino". Como complemento, Bettio e Martins (2004) explicam que o objeto de aprendizagem deve ter o propósito educacional e, principalmente, precisa estimular a reflexão dos alunos, para o auxílio na aprendizagem.

Assim, o emprego de objetos de aprendizagem, no processo de ensino, segundo Nunes (2004 apud Scolari, Bernardi, Cordenonsi, 2007, p. 4), traz maior flexibilidade para poder criar um ambiente em que todos os alunos fiquem interessados, consigam seguir o ritmo da aula e alcançar os objetivos traçados.

Portanto, para que seja desenvolvido um objeto de aprendizagem, Macedo e Chiaramonte (2007) salientam que é necessário o planejamento e o auxílio de uma equipe interdisciplinar que produz todo o conceito, de acordo com as necessidades apresentadas pelos estudantes, cabendo ao programador o papel de preparar todo o planejamento, sendo que, nesse momento, o mesmo propõe adequações para que seja possível ajustar a teoria à prática.

Após a construção de um objeto de aprendizagem, existem outras etapas, que são a aplicação da ferramenta criada e a sua análise, a fim de verificar a eficácia no processo de ensino-aprendizagem.

Logo, o foco do estudo foi investigar se um objeto de aprendizagem pode ser eficaz como uma ferramenta no processo de ensino-aprendizagem, em uma escola pública de ensino fundamental.

Desse modo, este trabalho teve como objetivo verificar a eficácia de um objeto de aprendizagem de geografia, criado em parceria com um professor da Educação Básica da rede pública de ensino, e comparar o desempenho acadêmico, em conteúdo específico de geografia, de dois grupos de alunos do 5으 ano do ensino fundamental, antes e após a intervenção com o uso do objeto de aprendizagem. 


\section{TECNOLOGIA NA ESCOLA}

A sociedade encontra-se em constante transformação, impulsionada pelas novas tecnologias. Nesse contexto, torna-se relevante estudar o uso das tecnologias nos vários âmbitos sociais, em específico na educação. É importante conhecer as possibilidades de aplicação em sala de aula e compreender as reais contribuições no processo de aprendizagem dos alunos (VALENTE, 2015; MORÁN, 2015).

Reis (2009) destaca que o uso da tecnologia na educação não é algo recente, acrescentando que a educação sistematizada, desde o seu início, utiliza diversas tecnologias educacionais, acompanhando sua contextualização histórica. Exemplifica que a tecnologia do giz e da lousa é adotada atualmente pela maioria das escolas, da mesma maneira que a tecnologia do livro didático persiste, em plena era da informatização. Ele aponta ainda que, na verdade, um dos grandes desafios do mundo contemporâneo consiste em adaptar a educação à tecnologia moderna e aos atuais meios eletrônicos de comunicação. Palfrey e Gasser (2011), Mattar (2010), Ansell (2016), Sancho-Gil e Padilla Petry (2016) endossam essa afirmação, ao apontar a urgência da necessidade de incorporar, de maneira significativa, as tecnologias digitais aos currículos escolares.

Certos autores, como Valente (2015), Borba e Penteado (2001), discutem a presença da informática nas atividades humanas, em particular nas atividades escolares, enfatizando que a entrada das mídias na escola está relacionada principalmente ao professor. Acrescentam ainda que, para o professor aprender a conviver com a mídia, é necessário um amplo trabalho de reflexão coletiva, revelando que o trabalho a ser realizado pelo professor irá requerer dedicação e participação da equipe docente.

Gadotti (2000) ressalta que a educação trabalha com a linguagem escrita, todavia, a cultura que temos hoje está impregnada por uma nova linguagem, televisiva e informatizada, em particular a linguagem da internet. Segundo Buim Arena (2015), as inovações tecnológicas, dos últimos anos, refletem no modo com os estudantes do século XXI aprendem, sendo necessário que as instituições escolares incorporem as mídias e a internet nas práticas pedagógicas. Vickery (2016) afirma que a escola do século XXI deve ter como foco práticas educativas inovadoras capazes de possibilitar o desenvolvimento da criticidade e autonomia nos estudantes.

Conforme Gadotti (2000), o maior obstáculo para o uso intensivo da informática é a cultura do papel. Nesse contexto, ele explica que os jovens, por ainda não terem internalizado inteiramente essa cultura, adaptam-se mais facilmente às novas tecnologias, em especial ao computador, do que os adultos, o que oferece um primeiro indício da resistência dos professores ao uso de tais tecnologias, no contexto escolar.

Na sociedade da informação, a escola deve servir de bússola para navegar nesse mar do conhecimento, superando a visão utilitarista de só oferecer informações "úteis" para a competitividade, para obter resultados. Deve oferecer uma formação geral na direção de uma educação integral. O que significa servir de bússola? Significa orientar criticamente, sobretudo as crianças e jovens, na busca de uma informação que os faça crescer e não embrutecer. (GADOTTI, 2000, p. 9) 
Servir de bússola representa direcionar a ação do aluno enquanto ser em construção, a fim de que consiga buscar, entender e crescer, utilizando os meios disponíveis e acessíveis para isso, entre os quais as informações oferecidas pela tecnologia atual, por isso, o trabalho com elas na escola é muito importante e significativo.

Por motivos como este, Carneiro, Maraschin e Tarouco (2001) definem a educação como um processo de aprendizagem que envolve trocas de informações constantes. Eles exemplificam também que, em uma sala de aula convencional, são usados imagens e sons, durante a troca, que professores e alunos veem e ouvem uns aos outros o tempo todo. Para eles, a comunicação acontece diretamente entre professores e alunos, com o uso de várias mídias combinadas, tais como um projetor, áudio e vídeo.

Atualmente, esse contato com a tecnologia está ampliado, pois os alunos utilizam os smartphones, os quais apresentam recursos de comunicação e a internet, com acesso a uma grande quantidade de informação. Segundo Tavares et al. (2015, p. 84), "as tecnologias mobile lançam novos desafios à compreensão dos processos de aprendizagem", colocando como ponto importante diferentes formas de acesso à informação e também modificando a forma de construir o conhecimento. Os autores discutem ainda o processo de ensino e aprendizagem, evidenciando o uso da tecnologia móvel como uma mudança significativa e não limitante mais apenas à sala de aula, porque esse acesso à informação e à aprendizagem pode ocorrer igualmente em espaços não formais e informais.

Apesar do emprego dos recursos móveis constituir oportunidades para o aprendizado, muitas vezes sua utilização não é direcionada para esse foco. De acordo com Cox (2003), os computadores são, sem dúvida, velozes e confiáveis depositários de informações. No entanto, para que essas informações se transformem em conhecimentos e/ou competências, tais equipamentos precisam ser criteriosamente trabalhados e explorados, no ambiente escolar. Pedro (2016), Valente (2015), Valcárcel e Repiso (2003) apontam que o grande desafio não é introduzir as tecnologias digitais nas escolas, mas promover, por meio desses recursos, atividades com intencionalidade pedagógica.

Em contrapartida, alguns autores, como Oliveira, Costa e Moreira (2001), revelam que a realidade atual mostra, a cada dia, mais a necessidade de a escola rever o seu projeto pedagógico, analisando e reconhecendo, de forma crítica e adequada, a presença dessas novas tecnologias na vivência dos alunos fora do contexto escolar.

Borges e França (2015) abordam o uso de laptops em sala de aula, buscando a reflexão sobre a necessidade de uma nova organização do trabalho pedagógico. Os autores examinam, no estudo, a organização do espaço com o uso dos laptops conectados na internet e como lidar com o conhecimento provocado pelo uso desses recursos conectados à internet. Observam que a presença dos laptops conectados na sala de aula provocou uma nova forma de organizar o trabalho pedagógico, de sorte que o professor não pode mais negligenciar o uso dessas tecnologias, em sala de aula. Refletem principalmente sobre importância do uso da tecnologia em sala de aula, com foco na formação do cidadão: 
A relevância do uso da tecnologia como acesso e formação para a construção de uma sociedade mais participativa, envolvida e com acesso aos recursos contemporâneos por ela empregados, é um dos grandes apontamentos de teóricos contemporâneos na área da tecnologia educativa (PESCADOR, 2012; LUEG, 2014; SANCHO-GIL; PADILLA PETRY, 2016).

\section{OBJETOS DE APRENDIZAGEM}

Atualmente, são vários os recursos usados no processo de ensino e aprendizagem, no entanto, certos autores, como Lueg (2014), Santos, Cruz e Pazzeto (2005), afirmam que não basta ter novas tecnologias disponíveis nas escolas, , mas é necessário que haja uma mudança de paradigma das concepções de ensino e aprendizagem, para que ela ocorra significativamente, citando como exemplo uma maior participação de alunos em aulas que enfatizem o emprego de programas capazes de favorecer a experimentação e a exploração, a aplicação de hipermídia e softwares de autoria, em contraste com uma menor participação com o uso de softwares de exercícios de repetição e prática, os quais acabam causando tédio e frustração nos alunos.

Milani (2001) assevera que o computador é o símbolo e principal instrumento do avanço tecnológico, por isso, não pode ser ignorado pela escola; no entanto, enfatiza que o desafio é colocar todo o potencial dessa tecnologia para auxiliar no aperfeiçoamento do processo educacional, com a finalidade de uni-la ao projeto escolar, conseguindo potencializar a formação de futuros cidadãos. Nessa perspectiva, Oliveira, Costa e Moreira (2001) afirmam que o uso da informática na educação exige um esforço dos educadores, a fim de que uma simples utilização do computador possa transformar-se em uma abordagem educacional que efetivamente favoreça o processo de conhecimento dos educandos. Para eles, se trabalhado dessa forma, a interação com os objetos, o desenvolvimento do pensamento hipotético e dedutivo, sua capacidade de interpretação e análise da realidade serão privilegiados.

\footnotetext{
Observa-se hoje os jovens com grande familiaridade em relação aos novos ambientes tecnológicos, por vivenciarem um processo de conhecimento paralelo ou anterior ao da escola, apoiado na tecnologia que vem impregnando de múltiplas formas na sociedade. (OLIVEIRA; COSTA; MOREIRA, 2001, p. 63)
}

Alguns recursos podem ser adotados para a integração da informática à escola, de maneira que pesquisadores como Longmire (2001), Sá Filho e Machado (2004) indicam vários fatores que favorecem o uso de objetos de aprendizagem (OA), em um contexto educativo.

Entre eles, citam a flexibilidade, relatando que os OA podem ser construídos de forma simples, sendo dessa forma, desde sua criação, flexíveis e reutilizáveis, pois podem ser reaproveitados sem custo algum com manutenção.

Os mesmos autores enfatizam também a facilidade para atualização dos OA, ocorrer em tempo real e de maneira muito simples. Complementam ainda com a 
customização, já que são adaptáveis a vários contextos educacionais, e a interoperabilidade, a qual permite que os OA possam ser adotados em qualquer plataforma de ensino do mundo.

Existem diversas definições para $\mathrm{OA}$, sendo que esta coleção adota a definição de David Willey (2000), que considera objeto de aprendizagem qualquer recurso digital que possa ser reutilizado para apoiar a aprendizagem.

Para Nascimento et al. (2009), os OA ou Learning Object (LO) são ferramentas reutilizáveis, que surgiram para facilitar, de maneira estruturada e organizada, o processo de ensino e aprendizagem.

Segundo Weller et al. (2003), o OA pode ser entendido como uma parte digital do material utilizado para favorecer a aprendizagem, dirigindo-se a um tópico claramente identificável ou ainda a um resultado da aprendizagem.

Complementando e apontando algumas implicações na educação, quanto ao uso dos OA, os autores destacam:

\footnotetext{
O uso da informática na educação exige em especial um esforço constante dos educadores para transformar a simples utilização do computador numa abordagem educacional que favoreça efetivamente o processo e conhecimento do aluno. Dessa forma, a sua interação com os objetos de aprendizagem, o desenvolvimento de seu pensamento hipotético dedutivo, da sua capacidade de interpretação e análise da realidade tornam-se privilegiados e a emergência de novas estratégias cognitivas do sujeito é viabilizada. (OLIVEIRA; COSTA; MOREIRA, 2001, p. 62)
}

Os educadores devem procurar formas de usar os objetos de aprendizagem, com o intuito conseguir proporcionar o maior desenvolvimento dos alunos, através de novas formas de se aprender, servindo-se da tecnologia.

Os OA são produzidos e disponibilizados geralmente em seus repositórios de objetos que conseguem reunir diversos recursos digitais com estrutura de taxonomização por conteúdo, habilidades, ano e outras características que favorecem a busca e o acesso, por parte do professor.

Kemczinski et al. (2012) apresentam uma metodologia e uma análise comparativa de diversas metodologias de objetos de aprendizagem, com o objetivo de identificar os meios que contribuem para atender às características pedagógicas e técnicas necessárias para o desenvolvimento de objetos de aprendizagem. A metodologia referida é composta por 6 etapas (análise, projeto, implementação, submissão, avaliação e publicação), nas quais se busca facilitar o processo de desenvolvimento dos OA, principalmente por parte dos pedagogos.

Braga, Pimentel e Dotta (2013) também pesquisam metodologias adequadas para a elaboração de objetos de aprendizagem, destacando as vantagens e deficiências em uma perspectiva do Design Instrucional. Identificam que, por envolver uma equipe multidisciplinar, a produção de objetos é bastante complexa. Observa-se, no estudo, que existe uma carência de metodologias de desenvolvimento de OA. Com base em uma metodologia empregada pelos Design Instrucionais, nomeada como INTERA 10, professores universitários foram treinados e relataram que, após o treinamento recebido, eles passaram a perceber a complexidade do processo de produção de um objeto de aprendizagem de qualidade e a importância do papel do professor, nesse processo de construção. 
Apesar das dificuldades na construção e limitações técnicas encontradas pelos professores para construir objetos de aprendizagem, sua utilização é importante para o aprendizado dos alunos:

Com relação aos aspectos pedagógicos, o desenvolvimento de OA com teorias pedagógicas permite que os alunos tenham um entendimento comum de determinado domínio e que possam desenvolver novos modelos consensuais, em colaboração com outros alunos e professores, tornando o processo de ensino/aprendizagem multidisciplinar. (SILVA et al. 2013, p. 73)

Com base na perspectiva apresentada, no próximo item, explicitaremos o percurso metodológico da pesquisa, enfocando os instrumentos adotados, local da pesquisa e seus participantes.

\section{MÉTODO}

Esta pesquisa teve caráter experimental, que, segundo Gil (2002), corresponde essencialmente a escolher um objeto de estudo, selecionar as variáveis que podem influenciá-lo e definir os métodos de controle e verificação dos efeitos que a variável produz no objeto. $\mathrm{O}$ autor ainda completa, afirmando que o pesquisador, nesse tipo de pesquisa, não é somente um observador, mas um agente ativo.

O objeto de aprendizagem foi desenvolvido em um laboratório de informática de uma Universidade particular do interior do Estado de São Paulo, à qual os pesquisadores são vinculados.

O estudo foi realizado em uma escola municipal situada em Guarapuã, distrito da cidade de Dois Córregos, no estado de São Paulo. Essa escola conta com um professor de educação infantil e 16 de ensino fundamental. Ao todo, a instituição possui 196 alunos, 17 professores, uma diretora, uma vice-diretora e mais 10 funcionários que prestam serviços de secretaria e limpeza. A escola foi selecionada, considerando-se o conhecimento de que a direção apoia iniciativas pedagógicas como a desenvolvida neste trabalho.

Participaram do estudo uma professora que atua no ensino fundamental, que aceitou colaborar com a pesquisa, e 25 alunos do 50 ano do ensino fundamental. Esses alunos são matriculados na sala da professora participante do estudo e foram, segundo critérios na avaliação inicial, divididos em dois grupos homogêneos: experimental e controle. Os procedimentos éticos foram adotados, todos os alunos assinaram o termo de assentimento e a professora, o termo de consentimento livre e esclarecido, a fim de participarem da pesquisa.

Os instrumentos de coleta e análise de dados foram desenvolvidos pelos pesquisadores em conjunto com a professora de sala. Foi elaborado um protocolo com perguntas relacionadas ao conteúdo programático e regras das atividades propostas pelo professor, para que fosse construído o OA. Essas questões ligadas ao conteúdo proposto foram importantes para definir as questões pedagógicas e conceituais do objeto construído. Esse protocolo teve como objetivo levantar informações associadas às regras das atividades, bem como feedbacks que seriam apresentados para os alunos, fornecendo orientações pedagógicas para a criação do recurso digital. Foram também formuladas, como instrumentos de coleta de dados, duas avaliações, uma inicial e outra final, com perguntas concernentes ao 
conteúdo curricular tratado no objeto de aprendizagem desenvolvido neste estudo. Esses instrumentos tiveram como foco identificar qual a evolução dos grupos experimental e controle, antes e após o processo de intervenção.

Outro instrumento utilizado foi o OA de geografia, desenvolvido pelos pesquisadores em conjunto com a professora de sala, intitulado "Regiões do Brasil", o qual foi preparado com os programas Flash Develop 3.0.2, Adobe Flash CS5 e Adobe Photoshop CS5.

Os procedimentos de coleta de dados desta pesquisa estão descritos a seguir.

Em conversa com a diretora da escola participante, a mesma ofereceu o local e indicou uma professora, a qual tem mais contato com a tecnologia e costumava usar a sala de informática.

A professora indicada e selecionada tinha 23 anos, iniciou sua carreira no magistério em 2003 e é formada em Letras Português/Espanhol. Na área de informática, possui curso básico sobre as ferramentas do pacote Office, além de conhecimentos adquiridos nas disciplinas relacionadas à tecnologia, frequentadas na universidade.

Com essa professora, foi realizada uma pequena capacitação de 3 horas, cuja finalidade foi explicar o que são e quais os tipos de objetos de aprendizagem. Essa capacitação foi norteada pelo livro Objetos de aprendizagem: uma proposta de recurso pedagógico, de autoria de Prata, Nascimento e Pietrocola (2007), que, em seu conteúdo, apresenta vários estudos realizados, empregando essa ferramenta, além de definir muito bem o seu conceito e auxílio, na educação.

Ao final da capacitação, foi feita a proposta para que a professora definisse um tema e, através dele, desenvolvesse atividades para se tornarem um objeto de aprendizagem. Foi então aplicado o instrumento de coleta de dados, um protocolo elaborado pelos pesquisadores, com foco no levantamento de informações pedagógicas e conceituais importantes para a construção do recurso digital. 0 protocolo foi preenchido pela professora, com o auxílio do pesquisador, o qual orientou o que esperava, em cada tópico apresentado. A ação de explicar item a item ajudou no entendimento e facilitou o preenchimento da professora participante do estudo. Com base nessas informações, foi possível, por conseguinte, construir o objeto de aprendizagem. As informações do protocolo foram importantes para a construção de um roteiro com alguns elementos que auxiliariam no processo de criação: título, tema, conteúdo, série indicada, enunciado das atividades, descrição das atividades e feedbacks.

Após o desenvolvimento do roteiro, o pesquisador voltou a reunir-se com a professora, de modo a tirar algumas dúvidas sobre a criação do objeto de aprendizagem e sugerir alterações para propor maior interatividade nas atividades.

Com a conclusão do roteiro, iniciou-se o desenvolvimento, no qual o pesquisador, com base no conteúdo descrito pela professora, criou um objeto de aprendizagem. Encerrada a elaboração, o objeto de aprendizagem passou pela apreciação da professora, que aprovou o recurso construído, validando os conceitos e as questões pedagógicas, autorizando sua utilização em sala de aula.

Foi pedido para a professora que preparasse uma aula direcionada para o tema do objeto de aprendizagem, para que os alunos participantes da pesquisa 
tivessem um conhecimento inicial do conteúdo tratado nesse objeto. Também foram formuladas, junto com a docente, duas avaliações com 15 perguntas de múltipla escolha relacionadas com os conteúdos do objeto de aprendizagem, sendo que as perguntas da avaliação final foram as mesmas da avaliação inicial, ou seja, foram mudadas as ordens das questões e alguns enunciados, porém, o conteúdo permaneceu o mesmo.

A aula da professora teve a duração de 50 minutos, durante a qual foi tratado o mesmo tema ligado ao objeto de aprendizagem, ou seja, siglas dos estados, as regiões do Brasil, principais características das regiões e análise de mapa. Como auxílio na aula, o professor utilizou um mapa do Brasil, o qual foi fixado na lousa, a fim de que todos os alunos pudessem acompanhar as informações passadas.

Após a anotação dos alunos, o pesquisador realizou a primeira coleta de dados, através da avaliação inicial, que continha perguntas relacionadas à aula ministrada. Todos os 25 alunos participaram e levaram 20 minutos para responder a todas as perguntas da avaliação. As avaliações foram corrigidas e os resultados do desempenho auxiliaram na divisão dos grupos, porque o número de acertos na avaliação foi o critério para definir os dois grupos. A divisão foi realizada, separando-se os alunos com alto e baixo desempenho nos dois grupos e deixandoos homogêneos. Foram então criados os dois grupos, denominados grupo-controle e grupo experimental.

No dia seguinte, ocorreu a segunda etapa da pesquisa, que separou os grupos experimental e controle, com o intuito de identificar a evolução dos alunos com a interação do objeto de aprendizagem criado, e sem a interação com o mesmo. 0 grupo experimental, composto por 12 alunos, foi até o laboratório de informática com o pesquisador, para, durante 30 minutos, interagirem com objeto de aprendizagem criado, sem a interferência do pesquisador, enquanto o grupocontrole ficou na sala de aula, fazendo atividades parecidas com as dispostas na ferramenta criada, porém, sem o uso do computador, nem do professor.

O professor foi orientado pelo pesquisador a não interferir nas atividades passadas na sala de aula, de forma que os alunos as realizaram somente com o auxílio do mapa, o qual ficou fixado na lousa da sala. O mesmo aconteceu no laboratório de informática, onde o pesquisador não interferiu em nenhum momento na realização da interação com o objeto de aprendizagem, somente para orientar na operação do computador, quando os alunos tinham dificuldade.

Os alunos na sala de informática ficaram dispostos nos 10 computadores disponíveis. Somente dois alunos ficam em duplas, sendo que o restante interagiu com objeto de aprendizagem sozinho. No caso dos alunos em dupla, foi orientado que deveriam alternar entre eles a manipulação do objeto de aprendizagem.

Ao final da interação, os alunos do grupo experimental voltaram para a sala de aula e, junto com o grupo-controle, foi efetivada a segunda coleta de dados, com a aplicação da avaliação final, a partir das mesmas perguntas da avaliação inicial, porém, em ordens diferentes e com pequena alteração nos enunciados, para que os alunos não percebessem a semelhança.

Os resultados foram tabulados, por meio de planilhas e gráficos, sendo comparados com o da primeira, com o intuito de verificar qual foi a evolução da aprendizagem dos alunos com e sem o emprego do objeto de aprendizagem desenvolvido. 
Após a coleta de dados, o grupo-controle foi levado para o laboratório de informática, para realizar a mesma atividade que o outro grupo, enquanto o grupo experimental permaneceu na sala de aula com a professora. Esse procedimento foi adotado para garantir a oportunidade de todos os participantes vivenciarem a utilização do objeto de aprendizagem.

\section{RESULTADOS E DISCUSSÕES}

Os resultados serão apresentados seguindo-se a ordem das etapas do procedimento investigativo descrito no método. Primeiramente, serão expostos os dados da elaboração do objeto de aprendizagem, seguidos do desempenho dos alunos na realização da avaliação inicial e, com ela, a divisão em dois grupos: controle e experimental. Após a apresentação desses dados, serão descritos os resultados da avaliação final e um comparativo da inicial com a final. É importante ressaltar que, depois da realização da primeira avaliação, os alunos passaram por um processo de intervenção, separados em dois grupos, de maneira que, somente após a intervenção, foram coletados os dados da avaliação final.

1. Elaboração do objeto de aprendizagem

Foi encaminhado para a professora um protocolo, como instrumento de coleta de dados para o desenvolvimento do objeto de aprendizagem. Esse protocolo foi desenvolvido pelos autores e destinado a levantar informações a respeito dos conceitos e orientações pedagógicas para a produção do objeto. 0 Instrumento coletou informações sobre o título do objeto de aprendizagem, tema, conteúdo proposto, ano/série para a qual seria indicado esse material, a descrição das atividades e todos os feedbacks de todas as atividades apresentadas como sugestão de desenvolvimento. Observou-se que o professor definiu como título as Regiões do Brasil, o tema de estudo foram as regiões brasileiras e todo o conteúdo direcionado para os nomes e siglas dos estados brasileiros, análise de mapas, apresentação e caracterização das regiões do Brasil e o tratamento da informação. A série indicada pelo professor foi o $5^{\circ}$ ano do ensino fundamental.

As atividades foram definidas e descritas, no protocolo, pelo professor. Os objetivos das atividades propostas foram de associar as siglas com os respectivos nomes dos estados brasileiros, foi também de colorir os estados brasileiros de acordo com as regiões a que eles pertencem, e analisar, rever e registrar informações. Após a especificação, foram descritas as atividades pela professora.

A professora detalhou que, na primeira atividade, deveria haver um mapa do Brasil contendo as siglas dos estados e uma lista com os nomes completos, para que os alunos conseguissem fazer a relação. Essa atividade foi desenvolvida de acordo com o que a professora solicitou.

A segunda atividade proposta pela professora foi de apresentar o mapa do Brasil contendo os estados, a fim de que os alunos pudessem colorir os estados conforme a cor de sua região especificada na legenda, dividindo o país em diferentes regiões.

A terceira atividade proposta pela professora foi de preencher lacunas. Foi solicitado que o aluno pudesse escrever nas lacunas, com o objetivo de completar as informações necessárias para identificar o seu aprendizado. 
A professora descreveu, no protocolo, os feedbacks necessários para as atividades realizadas pelos alunos, de modo a oferecer interatividade na realização das ações dos alunos, tornando o recurso mais interessante para os alunos.

$\mathrm{Na}$ atividade 1, foi exposta uma explicação de que o Brasil foi dividido em 26 estados, além do Distrito Federal. Foi informado também que todos esses estados se dividem em 5 grandes regiões. Dessa forma, foi direcionada a seguinte pergunta para os participantes: "Você sabe quais são essas regiões?"

Conforme o aluno respondia corretamente a atividade, o feedback era apresentado:

“Região Nordeste - Nove estados formam a região Nordeste: Bahia, Sergipe, Alagoas, Pernambuco, Paraíba, Rio Grande do Norte, Ceará, Piauí e Maranhão. As frutas características dessa região são o Cupuaçu e o Caju. Um personagem histórico que viveu nessa região foi Virgulino Ferreira da Silva, mais conhecido como Lampião, o rei do cangaço".

“Região Norte - A região Norte, a maior região brasileira, é formada por sete estados: Rondônia, Acre, Amazonas, Roraima, Amapá, Pará e Tocantins. Nessa região vive a maioria da população indígena do país. Ela possui uma grande extensão de floresta amazônica, que é a maior floresta tropical do mundo, sendo que nela existe uma grande variedade de espécies de seres vivos e alguns deles ameaçados de extinção, como o peixe-boi".

"Região Sudeste - A região Sudeste é formada pelos seguintes estados: São Paulo, Rio de Janeiro, Espírito Santo e Minas Gerais. Nessa região encontram-se os maiores e mais importantes setores industriais, comerciais e financeiros do país. Como característica marcante dessa região, temos o Cristo Redentor, que fica no estado do Rio de Janeiro, e as suas indústrias".

"Região Sul - Formam a região Sul os estados do Rio Grande do Sul, Santa Catarina e Paraná. Essa região é a mais fria, pois está abaixo do trópico de Capricórnio, sendo comum, no inverno, geadas e nevascas em alguns locais. No estado do Paraná, é possível apreciar a beleza das cataratas do Rio Iguaçu, que tem uma queda d'água de 90 metros de altura".

"Região Centro-Oeste - Formada pelos estados de Goiás, Mato Grosso, Mato Grosso do Sul, além do Distrito Federal, a região Centro-Oeste localiza-se no interior do território brasileiro. O cerrado é a vegetação predominante da região Centro-Oeste, sendo o Tamanduá um animal encontrado nesse tipo de vegetação".

Com relação à atividade 2 do objeto de aprendizagem, a professora descreveu a atividade, oferecendo uma sequência ao proposto na atividade anterior: "Atividade 2: Agora que conhecemos os estados e as regiões, vamos nos localizar no mapa, descobrindo qual é o nosso estado e a que região ele pertence".

Na última atividade do objeto de aprendizagem, a professora relatou o que o aluno aprendeu nas atividades propostas e também ofereceu a oportunidade de jogar novamente, iniciando as atividades: "Atividade 3: Nestas atividades, você aprendeu os nomes e as siglas de todos os estados brasileiros e as regiões a que cada um deles pertence. Deseja jogar novamente?"

De acordo com Lima et al. (2007), a equipe pedagógica dá o início no processo de desenvolvimento de um $\mathrm{OA}$, através de sua definição, escolhendo como será 
tratado o tema e descrevendo as atividades. A participação de professores na elaboração de OA e no planejamento das atividades que serão desenvolvidas no ambiente de informática proporciona maior intencionalidade e eficácia às atividades que são implementadas por meio de recursos tecnológicos (VALCÁRCEL; REPISO, 2003; PEDRO, 2016).

Esse roteiro serviu como base para o desenvolvimento do objeto de aprendizagem, de maneira que, através das descrições das atividades propostas pela professora, nesse protocolo, foram baseadas todas as telas existentes no objeto de aprendizagem. Outras informações primordiais encontradas no roteiro foram os feedbacks, os quais, segundo Prata, Nascimento e Pietrocola (2007), visam a "[...] instigar os alunos a demonstrarem seus conhecimentos e pensamentos sobre as questões propostas, provocando-os com situações que lhes permitam revisar e ajustar as ideias".

O objeto de aprendizagem "Regiões do Brasil" foi desenvolvido a partir do protocolo preenchido pela professora.

Na Figura 1, pode-se visualizar a tela de abertura do objeto de aprendizagem, que é composta pelo título e o acesso ao objeto, por meio do botão jogar.

Figura 1 - Tela de abertura do objeto de aprendizagem.

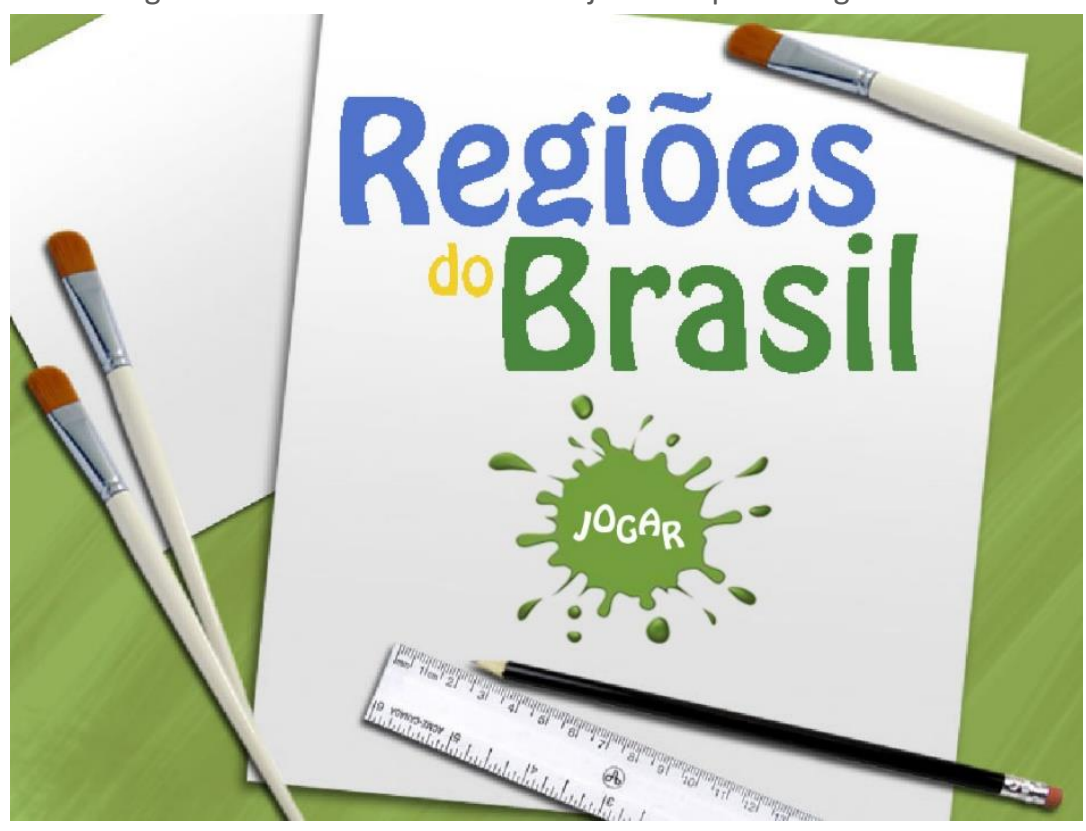

(Fonte: Elaboração própria)

Ao iniciar, o aluno é direcionado para a primeira atividade, que tem a proposta de arrastar os nomes dos estados nos locais corretos no mapa. O mapa no qual o aluno arrasta os nomes tem todos os estados do Brasil, com as suas respectivas siglas; caso seja arrastado um nome para um local errado, automaticamente ele volta para o seu local inicial. Dessa forma, não é possível encaixar os nomes em estados errados. 


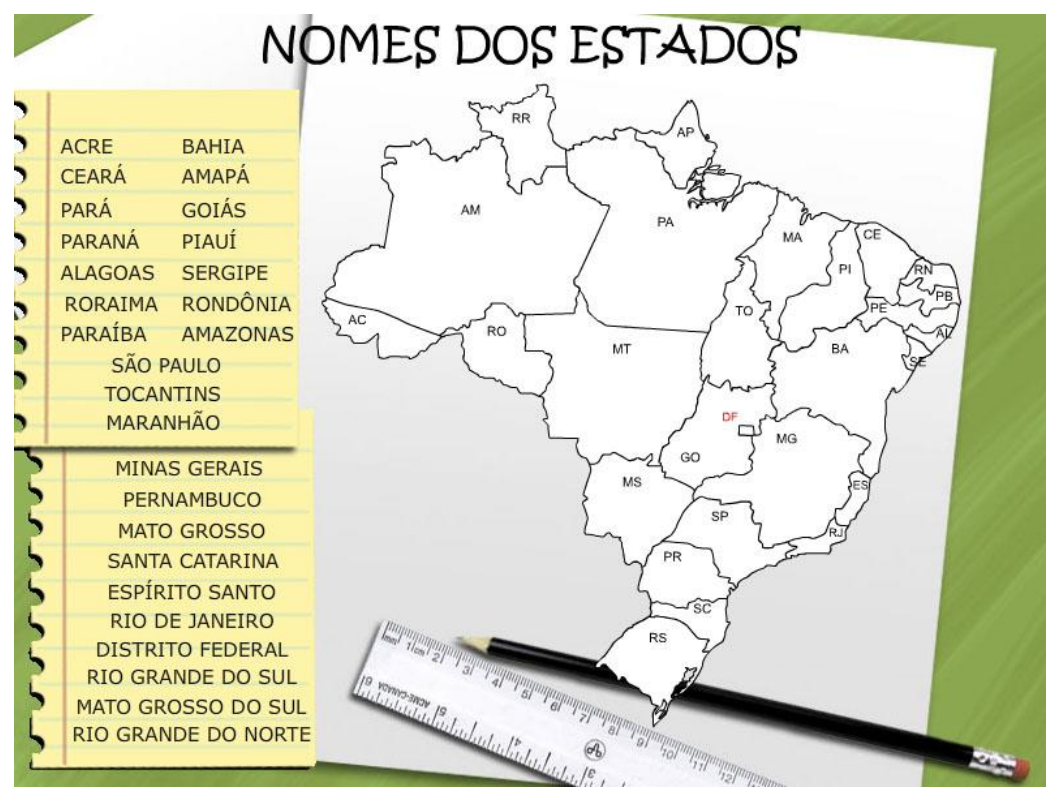

(Fonte: Elaboração própria)

Ao término desta atividade é exibido um breve feedback da primeira atividade, já trazendo uma pergunta para iniciar a segunda atividade. Deve-se clicar no " $X$ " para fechar a tela e iniciar a Atividade 2.

Figura 3 - Feedback da atividade 1.

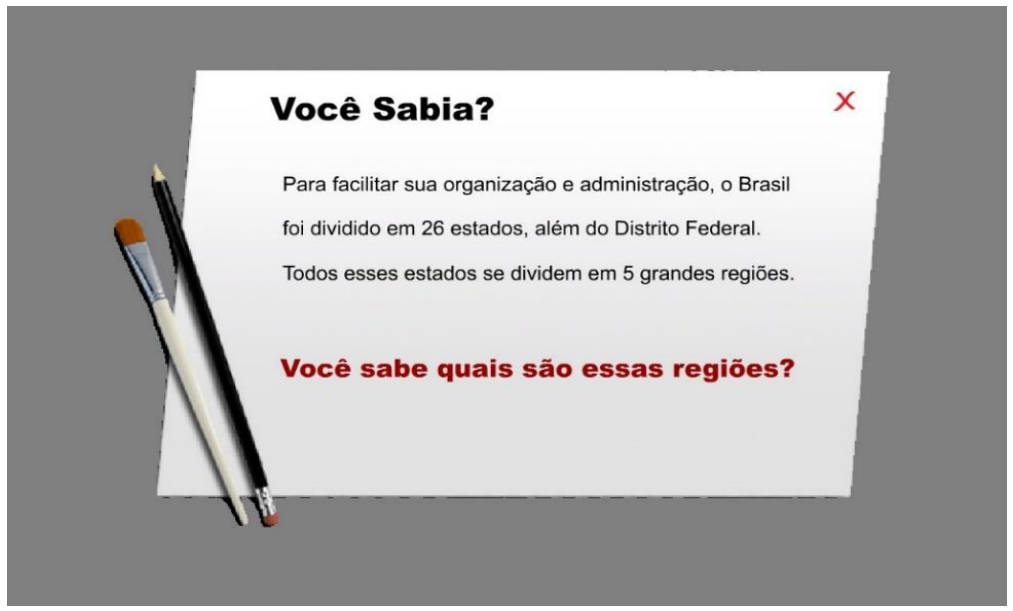

(Fonte: Elaboração própria)

A Atividade 2 é relacionada ao conceito de regiões, na qual se deve pintar os estados, seguindo-se a cor da região a que eles pertencem, sendo que, a fim de deixar mais lúdico e representativo esse procedimento, o mouse foi transformado em um pincel. Para colorir, primeiramente deve-se clicar na cor desejada, para depois pintar o estado. Quando é pintado corretamente, o estado muda para a cor certa, porém, se estiver errado, automaticamente aparece um sinal de " $X$ ", indicando que está errado. Quando todos os estados de uma determinada região são pintados, é aberta uma tela de feedback, trazendo algumas informações sobre aquela região. Nessa tela foram colocadas fotos para representar melhor as principais características das regiões, de sorte que todas as regiões possuem um 
feedback personalizado. Para que o aluno continue a atividade, deve-se clicar " $\mathrm{X}$ " para fechar a janela.

Figura 4 - Atividade 2: Colorindo as regiões do Brasil

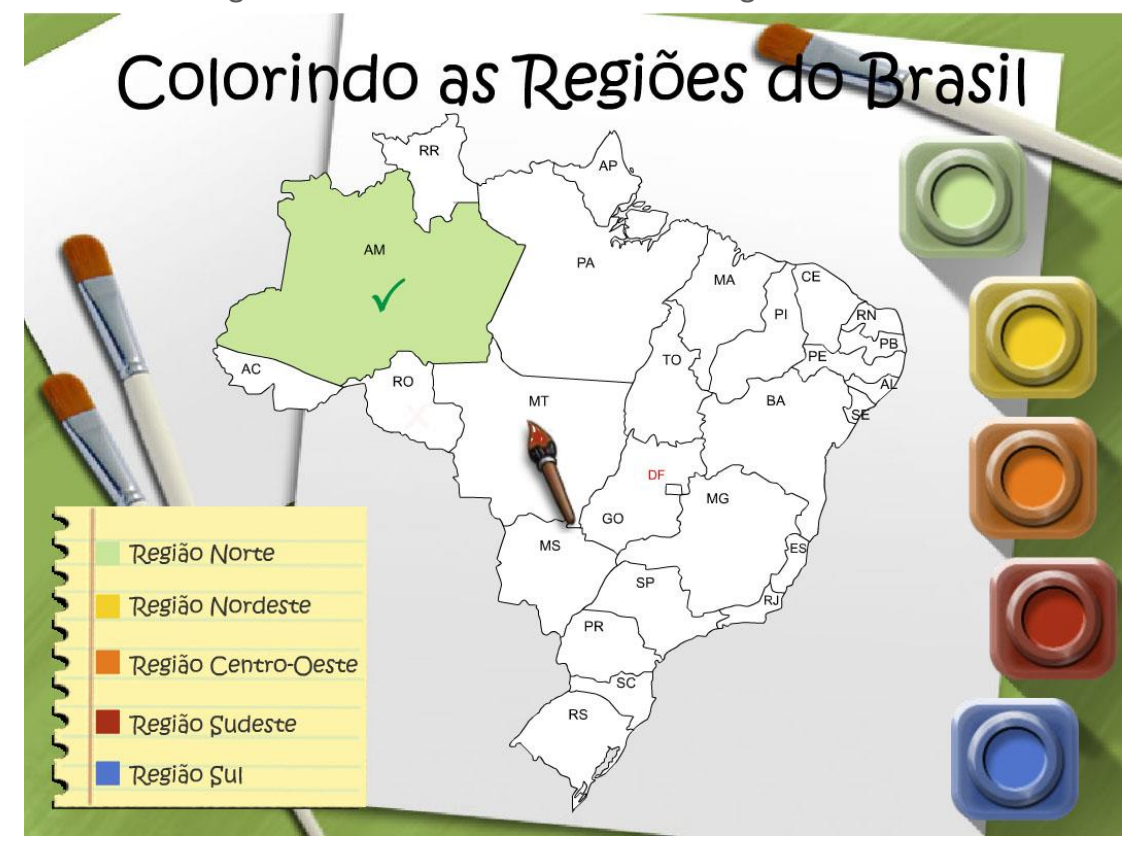

(Fonte: Elaboração própria)

Figura 5 - Feedback da região nordeste.

Nove estados formam a região Nordeste: Bahia, Sergipe, Alagoas, Pernambuco, Paraíba, Rio Grande do Norte, Ceará, Piauí e Maranhão. As frutas caracteristicas dessa região são o Cupuaçu e o Caju. Um personagem histórico que viveu nessa região foi Virgulino Ferreira da Silva, mais conhecido como Lampião, o rei do cangaço.
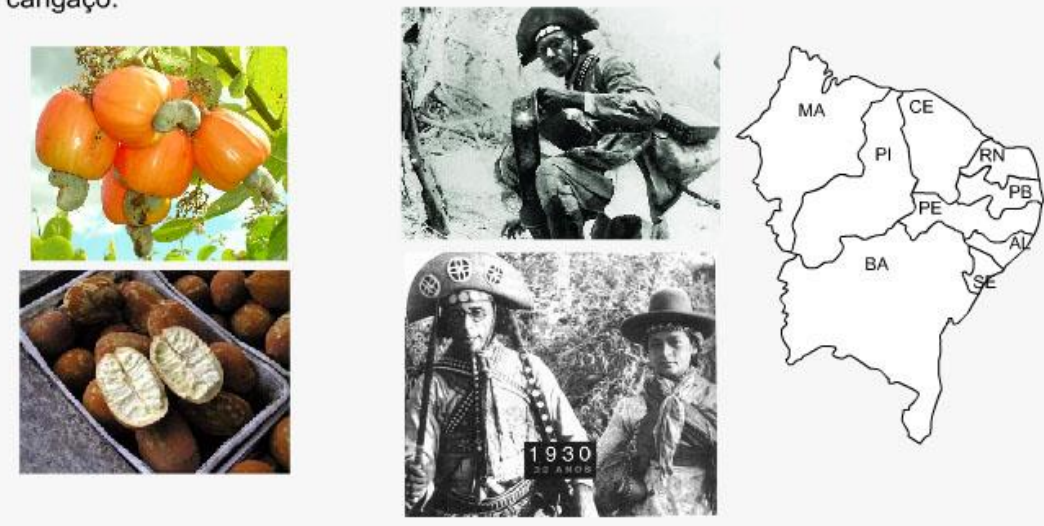

(Fonte: Elaboração própria) 


\section{Região Norte}

A região Norte, a maior região brasileira, é formada por sete estados: Rondônia, Acre, Amazonas, Roraima, Amapá, Pará e Tocantins. Nesta região vive a maioria da população indigena do pais. Ela possui uma grande extensão de floresta amazônica, que é a maior floresta tropical do mundo, sendo que nela existe uma grande variedade de espécies de seres vivos e alguns deles ameaçados de extinção, como o peixe-boi.

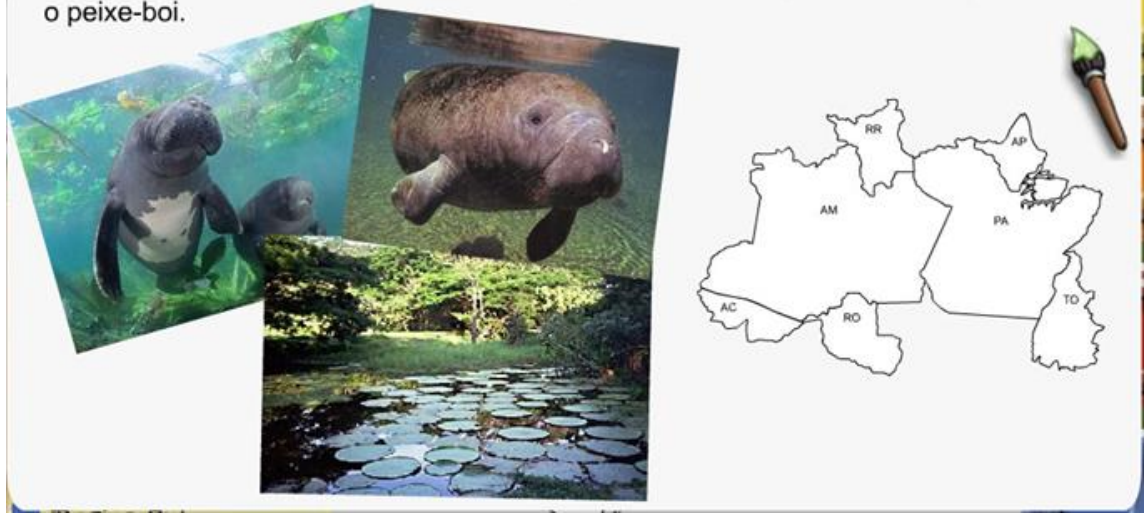

(Fonte: Elaboração própria)

Figura 7 - Feedback da região sudeste.

Região Sudeste

A região Sudeste é formada pelos seguintes estados: São Paulo, Rio de Janeiro, Espirito Santo e Minas Gerais. Nessa região encontra-se os maiores e mais importantes setores industriais, comerciais e financeiros do país. Como característica marcante dessa região temos o Cristo Redentor que fica no estado do Rio de Janeito $\mathrm{e}$ as industrias.

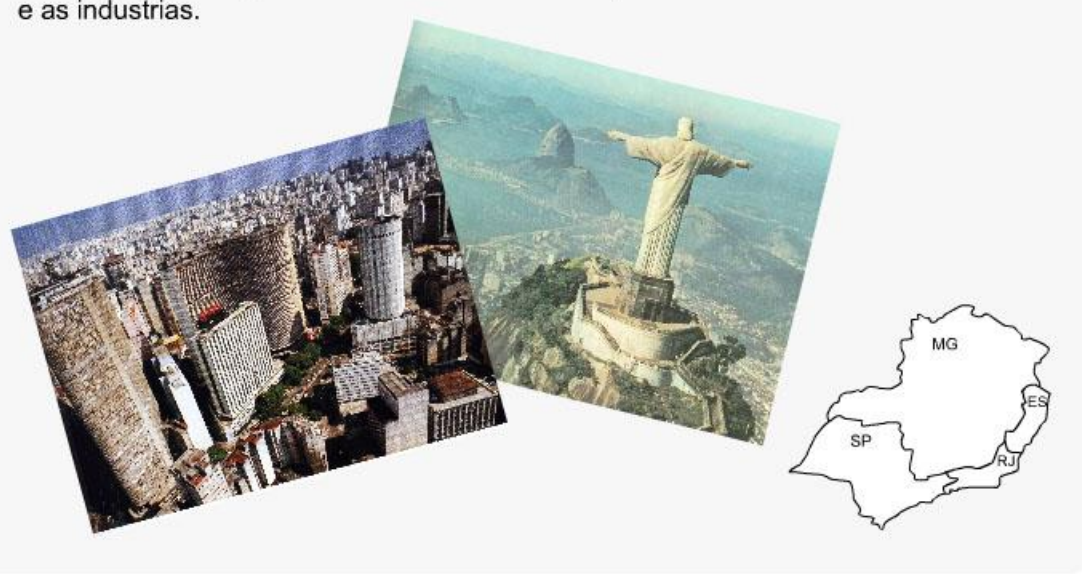

(Fonte: Elaboração própria) 
Formam a região Sul os estados do Rio Grande do Sul, Santa Catarina e Paraná. Esta região é a mais fria, pois está abaixo do trópico de Capricórnio, sendo comum no inverno geadas e nevascas em alguns locais. No estado do Paraná é possivel apreciar a beleza das cataratas do Rio Iguaçu que tem uma queda-d'água de 90 metros de altura.

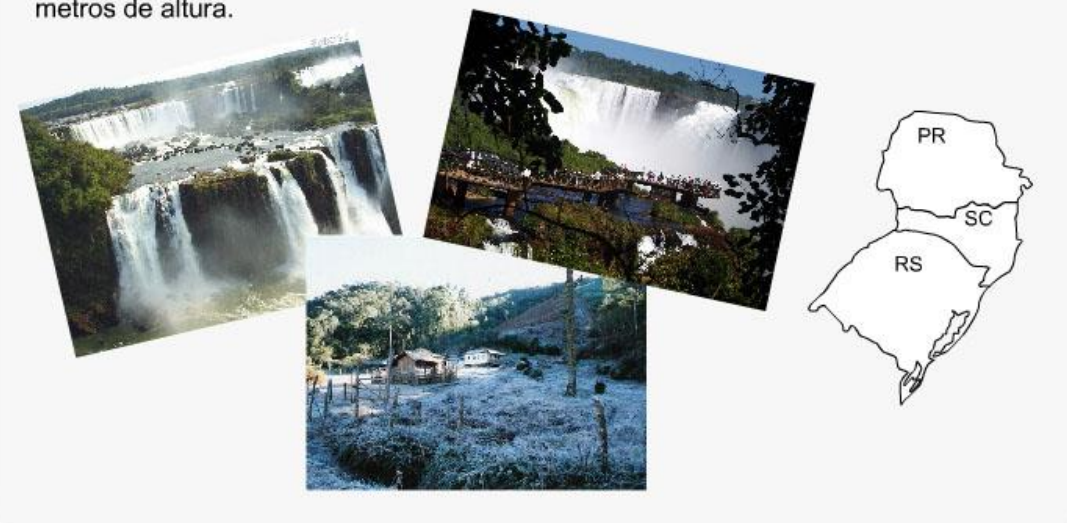

(Fonte: Elaboração própria)

Quando todas as regiões estiverem pintadas, automaticamente se abrirá uma tela de feedback da atividade encerrada, descrevendo o que deve ser feito na proposta seguinte. A fim de que seja iniciada a atividade 3, o aluno deverá clicar no botão "X".

Figura 9 - Feedback da atividade 2.

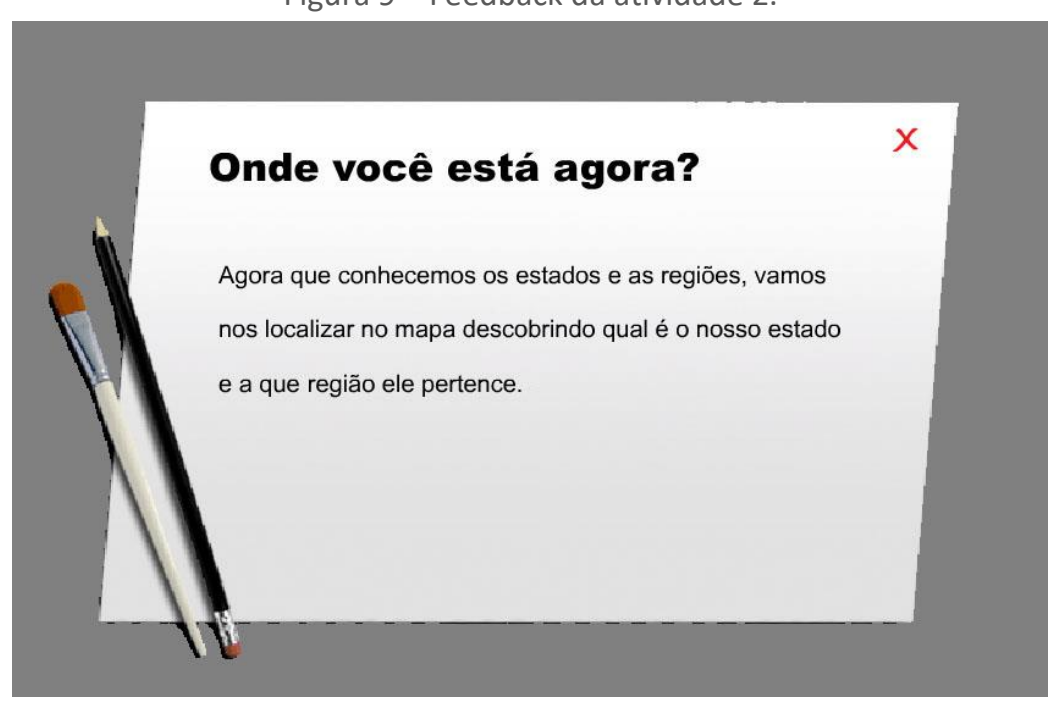

(Fonte: Elaboração própria)

A atividade 3 tem o objetivo de fazer com que o aluno se localize dentro do mapa, ocasião na qual ele deverá indicar o estado e a região em que mora, além de fazer uma análise do mapa, para descobrir qual região não faz divisa com a sua. O aluno precisa completar a frase que aparece na atividade e, para isso, primeiramente ele deve clicar no mapa e escolher o estado onde mora, depois 
arrastar os nomes das regiões para os locais corretos. Quando é clicado no mapa, automaticamente, é preenchido o nome do estado no espaço reservado para ele.

Nesta atividade, existe um botão chamado "Corrigir", que deve ser apertado para a correção da atividade; caso alguma resposta esteja errada, ela voltará para o seu lugar de origem ou se apagará do espaço, dando a chance de refazer somente o que está errado.

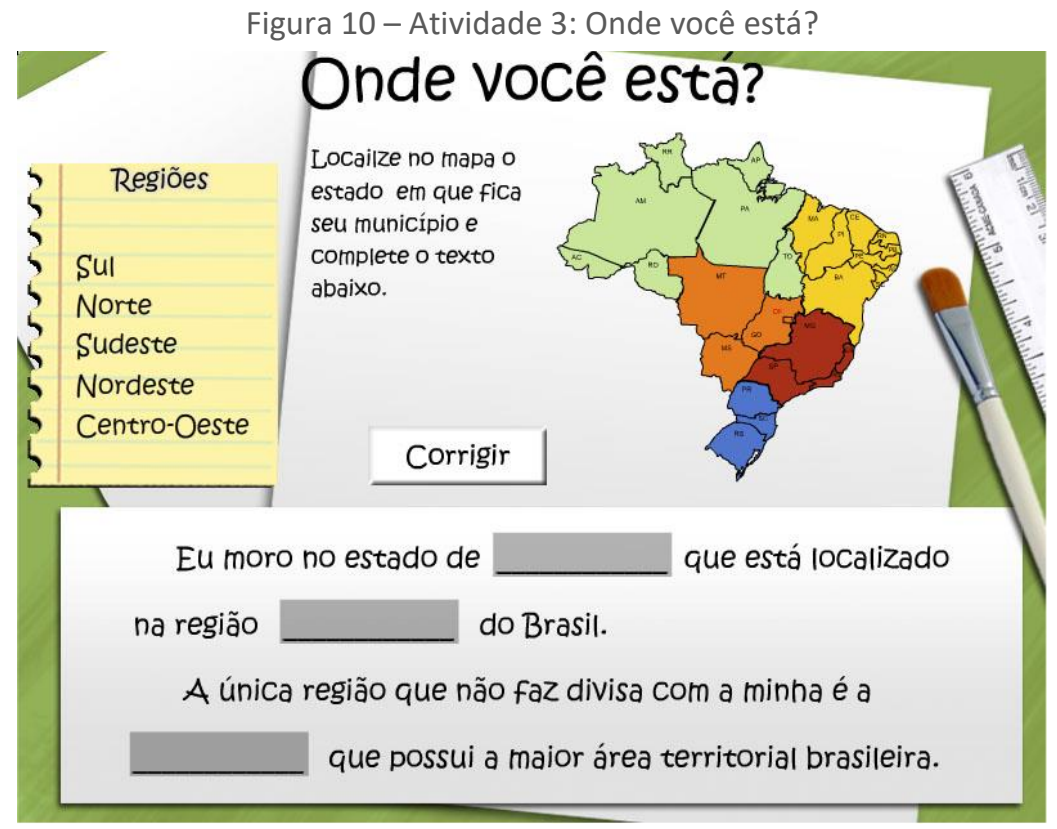

(Fonte: Elaboração própria)

Especificamente nessa atividade, as respostas da atividade são direcionadas para o estado de São Paulo, ou seja, se o aluno responder que mora em outro estado, no momento da correção, a resposta será considerada errada. Dessa forma, essa atividade possui uma característica de regionalização, uma vez que pode ser aplicada somente ao estado de São Paulo.

Quando as respostas de todos os espaços estiverem corretas, é aberta a tela com o feedback final da atividade e do objeto de aprendizagem. Nessa tela, o aluno tem a opção de escolher se quer jogar novamente, clicando o botão "Sim", ou sair do objeto de aprendizagem, clicando o botão "Não". Se escolher a opção de jogar novamente, ele será redirecionado outra vez para a primeira atividade. 


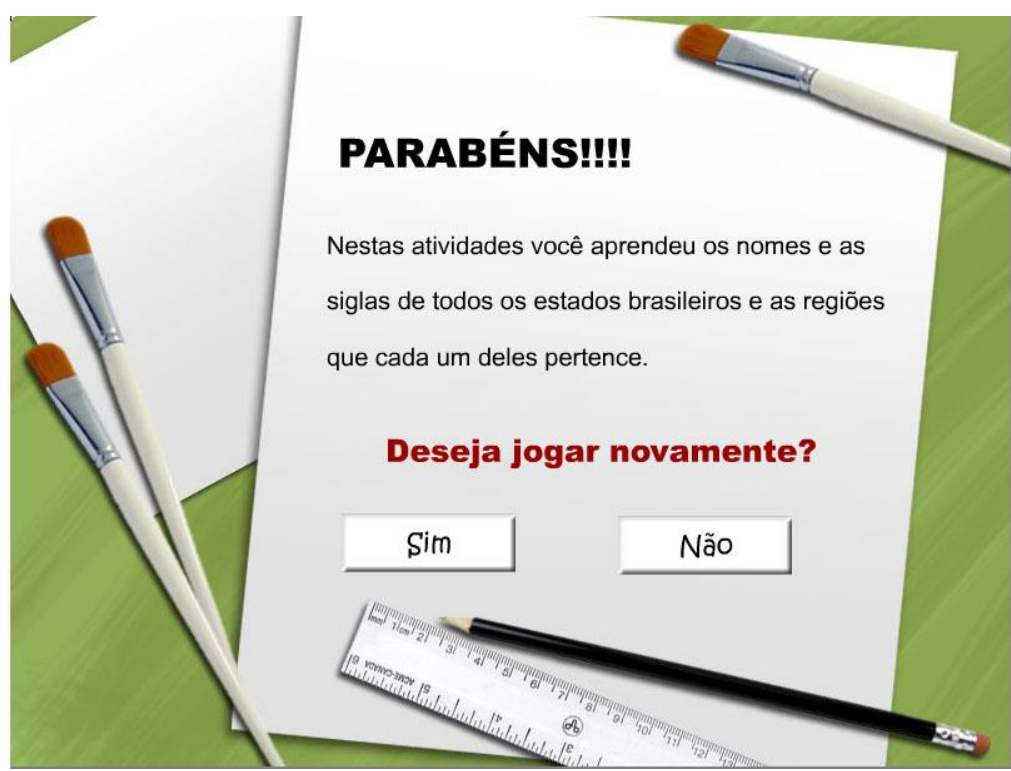

(Fonte: Elaboração própria)

\section{Aplicação da Avaliação Inicial}

A aplicação da Avaliação inicial, antes do processo de intervenção, ocorreu com os 25 alunos do 50 ano do ensino fundamental, e o instrumento aplicado foi constituído de 15 questões sobre o mesmo conteúdo proposto para ser trabalhado, tanto com o grupo-controle, em sala de aula com a professora, como no uso do objeto de aprendizagem no laboratório de informática, com o grupo experimental.

Observou-se que, das 15 questões aplicadas, 9 delas foram respondidas com uma porcentagem de acerto maior que 50\%, ficando apenas 6 abaixo dessa porcentagem. A questão de número 3 foi a que obteve maior índice de acerto, com resultado de $96 \%$, enquanto as perguntas 6,10 e 12 obtiveram a menor porcentagem de acerto, com $24 \%$ cada.

Desses resultados, pode-se afirmar que o grande percentual de acerto referente à pergunta 3 está ligado diretamente ao conhecimento prévio dos alunos sobre o assunto a ser estudado, além de estar relacionado ao grau de dificuldade da questão, pois a pergunta era para o aluno assinalar a sigla do seu Estado, entre 4 diferentes opções. Os resultados mostraram que os alunos sabiam a resposta, antes do processo de intervenção.

Quanto às perguntas que tiveram o menor índice de acerto, pode-se atribuir o fato de que se tratava de questões que exigiam maior análise e reflexão dos alunos, de modo a chegarem a alguma conclusão, naturalmente gerando mais erros. As questões eram sobre as regiões do país.

Pode-se analisar ainda, na aplicação do instrumento, os acertos por aluno, já que os alunos foram nomeados por: A1, A2, A3... A25, garantindo o anonimato dos participantes.

Observou-se que o aluno A1 foi quem obteve o maior número de acertos, alcançando o máximo obtido na atividade. Em contrapartida, o aluno A13 teve a 
menor quantidade de acertos entre todos os alunos, tendo como resultado apenas 3 acertos. Para essa avalição, a média aritmética de acertos por aluno foi de 9 .

Com as informações dos índices de acertos por alunos, foi possível dividi-los em dois grupos com níveis heterogêneos, utilizando como critério o número de acertos obtidos nas perguntas da atividade inicial. Os alunos foram repartidos em dois grupos: grupo-controle e grupo experimental.

O grupo-controle recebeu 13 integrantes e a média de acerto desses alunos, na avaliação inicial, foi de 8,54\%. A distribuição foi realizada de forma igualitária, para que os dois grupos tivessem alunos com alto e baixo rendimento, na avaliação aplicada na amostra. $O$ grupo experimental recebeu 12 integrantes, com resultado, na média de acertos, de $8,58 \%$.

A escolha de deixar um a menos no grupo experimental foi tomada pela necessidade de acomodar melhor os alunos na sala de informática, a qual tinha disponíveis 10 computadores para uso. Portanto, com essa escolha, diminuiu-se a necessidade de mais um grupo ter de ficar em dupla.

Através da análise geral dos resultados dos alunos, na avaliação inicial, podese considerar que a sala obteve, na média, $60 \%$ de acertos, somente com a aula ministrada pela professora participante da pesquisa.

\section{Aplicação da Avaliação final}

Após o processo de intervenção, o qual consistiu na realização de uma aula de 50 minutos, no laboratório de informática, com o grupo experimental interagindo diretamente com as atividades do objeto de aprendizagem, sem auxílio do pesquisador, enquanto, ao mesmo tempo, os alunos do grupo-controle concretizavam outras atividades, mas com o mesmo conteúdo apresentado no objeto de aprendizagem com a professora em sala de aula, pôde-se retornar todos para a sala de aula e aplicar a Avaliação Final para os dois grupos. É importante ressaltar que as questões da avaliação final foram as mesmas aplicadas na avaliação inicial, modificando-se somente a ordem e algumas informações no enunciado, mas se mantendo o mesmo conteúdo e grau de dificuldade.

A avaliação final foi efetuada com o intuito de identificar a evolução dos alunos com relação à atividade inicial. Observou-se que as perguntas 1 e 2 da avaliação final foram as que obtiveram maior porcentagem de acerto, com $96 \%$ e $92 \%$, respectivamente. A pergunta 10 obteve a menor porcentagem de acerto, com $40 \%$.

Pode-se atribuir o resultado satisfatório de acertos, na questão 2, à circunstância de se tratar de uma questão mais relacionada com a realidade que os alunos vivenciam, pelas atividades práticas encontradas nas atividades com o objeto de aprendizagem e até mesmo pelas atividades realizadas na sala de aula. Quanto à pergunta 1, podemos atribuir os acertos à ênfase que o professor deu, durante a aula, sendo igualmente importante ressaltar que essa pergunta foi a mesma que apresentou maior resultado, na avaliação inicial. Trata-se da questão que solicitou associar a sigla ao estado em que o aluno vive, sem muito desafio para os estudantes.

A razão de a questão 10 obter o menor percentual de acerto deve-se pelo fato de exigir grande análise e reflexão, além da memorização, pois, no momento da 
avaliação final, os alunos não dispunham do material de apoio como o mapa ou o objeto de aprendizagem.

Através da avaliação final, podemos igualmente analisar os resultados encontrados, sendo que os alunos A1 e A14 foram os que obtiveram o maior número de acertos: acertaram todas as questões, obtendo um resultado de $100 \%$. Foram seguidos de $\mathrm{A} 5$ e A16, que obtiveram 14 acertos das 15 questões propostas na avaliação final. Em contrapartida, o aluno A24 teve a menor quantidade de acertos entre todos os participantes, tendo como resultado apenas 4 acertos. Para essa avaliação final, a média dos alunos foi de 10 acertos, terminando com $67 \%$ de aproveitamento geral.

4. Comparação dos grupos nas avaliações inicial e final

Diante dos resultados da avaliação final, pode-se realizar uma comparação dos dados encontrados nas duas avaliações.

A Figura 12 apresenta os dados do grupo-controle referentes aos acertos da avaliação inicial comparados com a avaliação final, e a diferença encontrada entre as duas avaliações. Observou-se que a maioria dos alunos do grupo-controle conseguiu uma evolução nos resultados da avaliação inicial, comparados com a avaliação final. Pode-se verificar que o aluno $A 5$ foi o que obteve a maior evolução no número de acertos, na avaliação final, ficando com 4 acertos a mais que a avaliação anterior. Os alunos A4, A7, A8, A10, A11, A12 e A13, em diferentes números, obtiveram acertos maiores na avaliação final do que na avaliação inicial. Já os alunos $A 1, A 3$ e A9) não revelaram melhoras, porém, mantiveram os resultados da avaliação inicial. Os alunos A2 e A6 tiveram o seu desempenho abaixo do apresentado na atividade inicial, ou seja, na última avaliação, acertaram menos do que na inicial. Isso pode ter ocorrido por distração dos alunos, durante a realização da avaliação.

A Figura 13 traz os resultados da comparação da avaliação inicial e final do grupo experimental. Pode-se observar que, com exceção do aluno A24, todos os demais conseguiram manter ou melhorar seus acertos, nas questões da avaliação final, em relação aos resultados da inicial. A24 evidenciou desempenho inferior na segunda avaliação, porque obteve 6 acertos na avaliação inicial e apenas 4 acertos, na final. Da mesma maneira, no grupo-controle esse fato também ocorreu com dois alunos; no experimental, isso se repetiu com um dos participantes. $\mathrm{O}$ aluno A19 revelou a maior evolução no grupo, com 4 acertos a mais na avaliação final, visto que, na primeira avaliação, acertou 9 questões e, na segunda avaliação, 13 das 15 questões avaliadas. Os alunos A20 e A23 não obtiveram melhoras na segunda avaliação, permanecendo com os mesmos resultados de acertos nas duas avaliações, com 8 e 6 , respectivamente. Os demais participantes desse grupo apresentaram, em diferentes níveis, resultados positivos na segunda avaliação, em relação à primeira. 
Figura 12 - Número de acertos por aluno - grupo-controle em avaliação inicial e final.

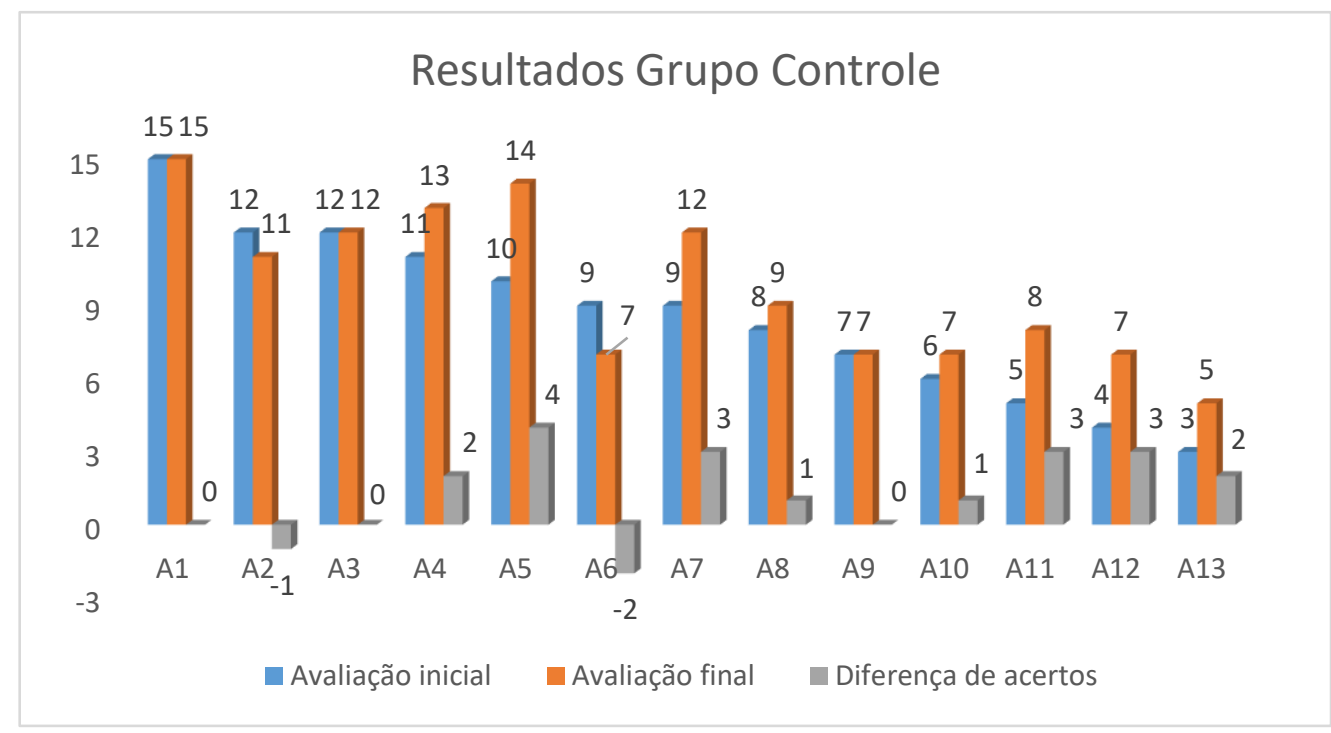

(Fonte: Elaboração própria)

Figura 13 - Número de acertos por aluno - grupo experimental em avaliação inicial e final

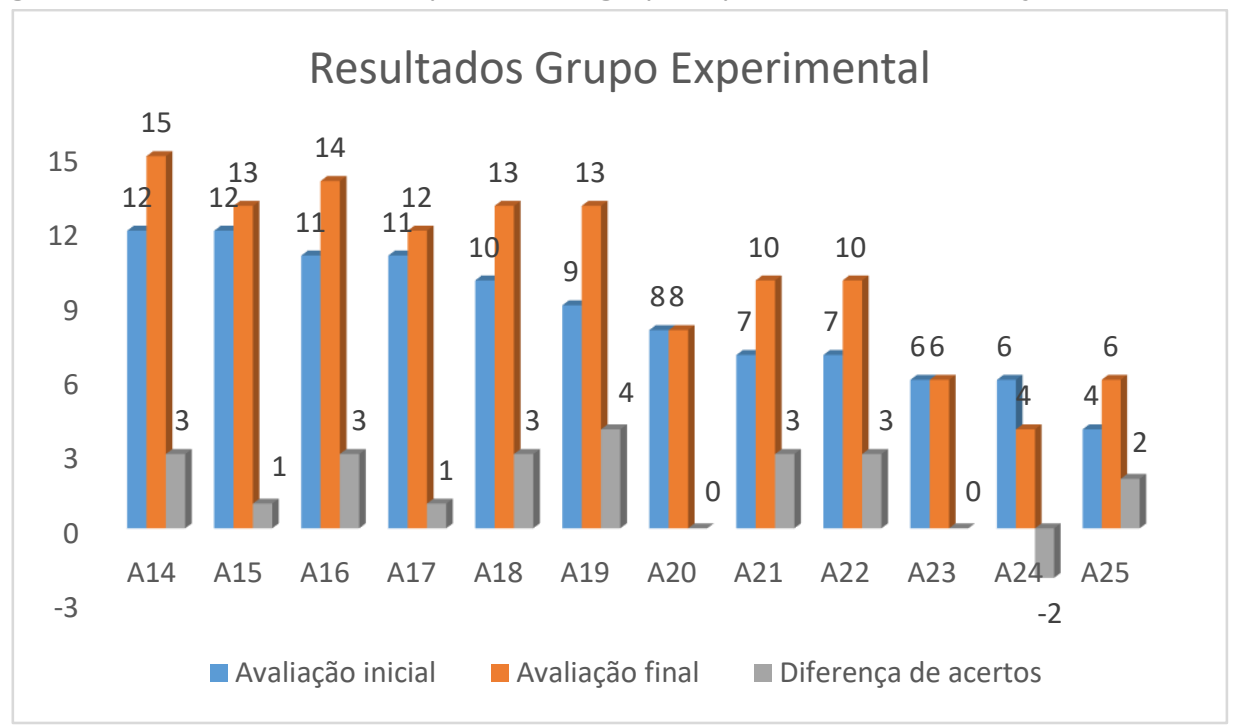

(Fonte: Elaboração própria)

Tabela 1 - Média das avaliações iniciais e finais, bem como a média da evolução dos grupos controle e experimental.

\begin{tabular}{cccc} 
& $\begin{array}{c}\text { Média acertos } \\
\text { (avaliação inicial) }\end{array}$ & $\begin{array}{c}\text { Média acertos } \\
\text { (avaliação final) }\end{array}$ & Média evolução \\
\hline Grupo Controle & 8,5 & 9,8 & $8 \%$ \\
Grupo Experimental & 8,6 & 10,3 & $12 \%$ \\
\hline
\end{tabular}

(Fonte: Elaboração própria)

Na Tabela 1, estão os dados obtidos pelos 25 alunos nas duas avaliações, antes e após a intervenção do professor com o grupo-controle e a intervenção do objeto de aprendizagem, com o grupo experimental. Os resultados alcançados indicam 
que, com o auxílio do objeto de aprendizagem, os alunos tiveram um maior índice de aproveitamento - de $12 \%$, contra $8 \%$ das atividades realizadas em sala de aula. Esse resultado mostrou-se favorável ao processo de ensino-aprendizagem, pois, segundo Silva-Filho (2007), quando são usados recursos de natureza interativa e multimídia, para o ensino-aprendizagem de novos conceitos abstratos, os assuntos podem ser vistos através de diversas perspectivas, favorecendo a compreensão do aluno. Alguns autores, como Savi e Ulbricht (2008), Frosi e Schlemmer (2010), reiteram que a utilização de $\mathrm{OA}$ e jogos no contexto educacional traz vários benefícios para os estudantes, como efeito motivador, facilitação da aprendizagem, aprendizagem por descoberta e desenvolvimento de estratégias. Valente (2015) e Morán (2015) destacam a necessidade de se promover práticas educativas inovadoras, as quais possibilitem uma aproximação com o cotidiano e a preferência de estudantes nascidos na era digital.

Sobre a adoção de OA, Costa, Caritá e Leal (2010) afirmam que estes podem agir como um acelerador no processo de ensino, além de deixar as aulas mais interessantes, diversificadas e adaptadas às características dos alunos.

Quanto aos resultados menores na avaliação final em relação à inicial, os resultados encontrados foram apresentados à professora participante da pesquisa, a qual relatou que os alunos A24 e A6 revelaram grande dificuldade de aprendizagem nas atividades em sala de aula, enquanto, com respeito ao aluno A2, atribui-se a desatenção como o único fator de ter apresentado índice abaixo do anterior. É importante ressaltar também que 4 alunos do grupo experimental efetivaram as atividades, empregando o objeto de aprendizagem juntos: formaram dois grupos de dois alunos, pois, devido ao número de computadores no laboratório, essa ação foi necessária. Contudo, fizeram a avaliação final sozinhos.

Ora, mesmo com a utilização do objeto de aprendizagem, não foi obtido um valor muito expressivo de evolução, porque, de acordo com Marques e Caetano (2002), para se conseguir usufruir ao máximo do computador, a escola deve ter uma proposta pedagógica coerente, a fim de que as ferramentas computacionais se tornem, de maneira efetiva, um diferencial para os alunos. Os autores complementam, ainda, frisando que o segredo para conseguir integrar as tecnologias com o ensino está ligado a um bom planejamento docente.

\section{CONCLUSÃO}

Com os resultados encontrados nesta pesquisa, evidenciou-se que o objeto de aprendizagem proporcionou uma evolução maior, no processo de ensinoaprendizagem, pois trouxe mais recursos de interatividade e propiciou aos alunos um estímulo diferenciado, distinto dos que estão habituados a realizar periodicamente, em sala de aula. Portanto, o objeto de aprendizagem criado mostrou ser um recurso interessante para ser usado no processo de ensinoaprendizagem, e poderá ser potencializado, se empregado como uma ferramenta de auxílio ao professor. Porém, outros dados precisariam ser levantados sobre a aula do professor, para se sustentar a diferença entre ambas as intervenções.

Apesar de a evolução encontrada não ser tão expressiva, acredita-se que, se o professor conseguir associar suas práticas em sala de aula com as novas tecnologias, principalmente os objetos de aprendizagem, de forma que consiga 
explorar a fundo todas as atividades nele apresentadas, os resultados para a aprendizagem dos alunos seriam mais satisfatórios, pois os estímulos estariam somados, potencializando ainda mais o ensino.

Marques e Caetano (2002) enfatizam que os professores capazes de adotar as novas tecnologias se tornam os "mediadores da aprendizagem" e passam a direcionar os alunos por caminhos que realmente os levarão ao conhecimento.

Os mesmos autores acrescentam que,

[...] para que ocorra a interação do aluno com a máquina, o professor precisa ser preparado para desempenhar o importante papel de mediador do conhecimento do aluno, não mais se restringindo à sua função de transmissor de informações e conhecimentos". (MARQUES; CAETANO, 2002, p.138)

Portanto, é relevante que o professor compreenda a importância dos objetos de aprendizagem, não como uma ferramenta que pode ser usada uma vez ou outra, mas que faça parte da sua atividade docente, porque poderá contribuir muito no processo de ensino-aprendizagem. Dessa maneira, Oliveira, Costa e Moreira (2001) afirmam que o professor tem de se empenhar para tornar a utilização do computador de uma forma que realmente favoreça o processo de ensino-aprendizagem, ressaltando que os objetos de aprendizagem podem auxiliar nesse processo, pois propiciam que os alunos criem novas estratégias para o desenvolvimento do seu conhecimento.

Conclui-se que objetos de aprendizagem podem ser adotados, no ambiente educacional, com aplicação de atividades interativas e estudo orientado pelo professor, a fim de que os resultados possam ser mais relevantes para a aprendizagem dos alunos. Entende-se a importância de estudos aplicados com o uso da tecnologia na sala de aula, pois muitos trabalhos discutem a relevância da tecnologia e os seus benefícios. Dessa forma, futuras pesquisas são necessárias para evidenciar resultados de aplicação em outras disciplinas e outras faixas etárias, de modo a debater as diferentes maneiras de aplicação das tecnologias, fornecendo subsídios para o professor trabalhar como mediador e planejar suas intervenções em sala de aula. 


\title{
Study on effectiveness of the implementation of a learning object with elementary school students
}

\begin{abstract}
This study aimed to verify the effectiveness of a geography learning object in the application with elementary students. For this, we constructed a learning object with the title Regions of Brazil and applied to 25 students of the 5 th year of elementary school. An initial assessment in order to analyze the students' knowledge of the topic and according to the results was carried out, students were divided into two homogeneous groups, control and experimental group. the application object in the computer lab for the experimental group was carried out while the control group performed activities on the subject with the teacher in the classroom. After the intervention groups underwent final evaluation. The results showed a difference of only four percent between the groups. The effectiveness of the resource created and its importance in the teaching-learning process can be concluded.
\end{abstract}

KEYWORDS: Learning Object. Geography. Teaching 
1 Disponível em: https://revistas.utfpr.edu.br/rbect.

\section{REFERÊNCIAS}

ANSELL, K. Aprendizagens ativas com as TICs. In: VICKERY, A. et al. Aprendizagem ativa nos anos iniciais do ensino fundamental. Porto Alegre: Penso, 2016. p. 127146.

BETTIO, R. W. de; MARTINS, A. Objetos de aprendizado: um novo modelo direcionado ao ensino a distância. 2004: Disponível em:

<http://www.universia.com.br/materia/materia.jsp?id=5938>. Acesso em: 15 out 2006.

BORBA, M.; PENTEADO, M. G. Informática e educação matemática. Belo Horizonte: Autêntica, 2001.

BORGES, M. A. F.; FRANÇA, G. O uso do laptop na sala de aula: uma nova forma de organização do trabalho pedagógico. Revista Científica Internacional Inter Science Place. Edição 19, volume 1, artigo n. 2, 2011.

BRAGA, J. C.; PIMENTEL, E.; DOTTA, S. Metodologia intera para o desenvolvimento de Objetos de Aprendizagem. In: II Congresso Brasileiro de Informática na Educação e XXIV Simpósio Brasileiro de Informática na Educação, 2013.

BUIM ARENA, D. As metamorfoses dos modos de ler: da rua para a escola. Revista Passage de Paris. n. 10, p. 114-124, 2015. Disponível em: http://www.apebfr.org/passagesdeparis/editione2015/articles/pdf/PP10_Dossier 8.pdf. Acesso em: 16 set. 2015.

CARNEIRO, M. L., MARASCHIN, C., TAROUCO, L. M. R. Interação: fator fundamental em cursos a distância. In: XXIX Congresso Brasileiro de Ensino de Engenharia, 2001, Porto Alegre. Anais do COBENGE 2001. Porto Alegre: ABENGE, 2001, p. 511-515.

COSTA, C. T. A.; CARITÁ, E. C.; LEAL, M. V. Avaliação qualitativa discente do objeto de aprendizagem divisão celular (mitose). In: Congresso Internacional de Educação a Distância, 16., 2010, Foz do Iguaçu. Anais... Foz do Iguaçu, 2010, 1 CD-ROM. 
FROSI, F.; SCHLEMMER, E. Jogos Digitais no Contexto Escolar: desafios e possibilidades para a prática docente. In: IX SBGames. Florianópolis. Anais... 2010. Disponível em:

http://www.sbgames.org/papers/sbgames10/culture/full/full13.pdf . Acesso em: 9 fev. 2016.

GADOTTI, M. Perspectivas atuais da educação. Porto Alegre, Ed. Artes Médicas, 2000.

GIL, A.C. Como elaborar projetos de pesquisa. 4. ed. São Paulo: Atlas, 2002.

KEMCZINSKI, A.; COSTA, I. A.; WEHRMEISTER, M. A.; HOUNSELL, M. S.; VAHLDICK, A. Metodologia para Construção de Objetos de Aprendizagem Interativos. In: Anais do 23 Simpósio Brasileiro de Informática na Educação. Rio de Janeiro, 2012.

LIMA, I. S. L.; CARVALHO, H. A.; Schlünzen Junior, K.; Schlünzen, E. T. M. . Criando Interfaces para objetos de aprendizagem. In: Objetos De Aprendizagem: Uma Proposta De Recurso Pedagógico. Brasília, 2007.

LONGMIRE, W. A Primer On Learning Objects. American Society for Training \& Development. Virginia/USA. 2001.

LUEG, C. F. Competencia digital docente: desempeños didácticos en la formación inicial del profesorado. Revista Científica de Educación y Comunicación. Educom: Cádiz-Espanha, nov., 2014, p. 55-71.

MACEDO, A. L.; CHIARAMONTE, M. Objeto de Aprendizagem: planejamento e implicações, 2007. Disponível em: <http://odai2006.pbworks.com/f/objeto_aprendizagem_implicacoes1.pdf>. Acesso em: 23 nov 2010.

MARQUES, A. C.; CAETANO, J. S. Utilização da informática na escola. In: MERCADO, L. P. L. (Org.). Novas tecnologias na educação: reflexo sobre a prática. Maceió: EDUFAL, 2002. p.131-168.

MATTAR, J. Games em Educação: como os nativos digitais aprendem. São Paulo: Pearson Prentice Hall, 2010.

MILANI, E. (2001). A informática e a comunicação matemática. In: K. S. Smole \& aprender matemática (pp.176-200). Porto Alegre: Artmed. 
MORÁN, J. Educação Híbrida: um conceito chave para a educação, hoje. In: BACICH, L.; NETO, A. T.; TREVISANI, F. M. (Orgs.) Ensino Híbrido: personalização e tecnologia na educação. Porto Alegre: Penso, 2015. p. 27-46.

NASCIMENTO, R. L.; AGUIAR, R.; V. SILVEIRA, R. M. C. F.; PILATTI, L. A. Técnica virtual no aprendizado de primeiros socorros. Simpósio Nacional de Ensino de Ciência e Tecnologia, Ponta Grossa, n. 1, 2009. Disponivel em: <http://www.pg.utfpr.edu.br/sinect/anais/artigos/11\%20TICnoensinoaprendizag emdecienciaetecnologia/TICnoensinoaprendizagemdecienciaetecnologia_artigo1 8.pdf> Acesso em: 15 out 2010.

OLIVEIRA, C. C. de; COSTA, J. W. da; MOREIRA, M. Ambientes Informatizados de aprendizagem: produção e avaliação de software educativo. Campinas: Papirus, 2001.

PALFREY, J; GASSER, U. Nascidos na era digital: entendendo a primeira geração dos nativos digitais. Porto Alegre: Artmed, 2011.

PEDRO, K. M. Estudo comparativo entre nativos digitais sem e com precocidade e comportamento dotado. (Doutorado em Educação) - Faculdade de Filosofia e Ciências, Unesp/Marília, 2016. Disponível em:

http://repositorio.unesp.br/handle/11449/143469. Acesso em: 01 set. 2016.

PESCADOR, C. M. Alunos nativos digitais e professores imigrante digitais. In: SOARES, E. M. S.; PETARNELLA, L. (Org.). Cotidiano escolar e tecnologias: tendências e perspectivas. Campinas: Editora Alínea, 2012. p. 15-30.

PRATA, C.; NASCIMENTO, A.; PIETROCOLA, M. Políticas para fomento de produção e uso de objetos de aprendizagem. In: PRATA, C.; NASCIMENTO, A. (Org.). Objetos de aprendizagem: uma proposta de recurso pedagógico. Brasília: MEC, SEED, 2007.

REIS, J. B. A. O conceito de tecnologia e tecnologia educacional para Alunos do ensino médio e superior. In: CONGRESSO DE LEITURA DO BRASIL, 17., 2009, Campinas. Anais do 170 COLE, Campinas, SP,: ALB, 2009. Disponível em: http://www.alb.com.br/anais17/txtcompletos/sem16/COLE_932.pdf. Acesso em: 31 nov. 2010. ISSN: 2175-0939

SÁ FILHO, C. S.; MACHADO, E. de C. O computador como agente transformador da educação e o papel do Objeto de Aprendizagem, 2004. Disponível em: <http://www.universia.com.br/matéria /materia.jsp?materia=5939>. Acesso em: 25 out 2010. 
SANCHO-GIL, J. M.; PADILLA PETRY, P. Promoting digital competence in secondary education: are schools there? Insights from a case study. Journal of New Approaches in Educational Research, 5 (1), p. 57-63. 2016.

SANTAELLA, L. Navegar no ciberespaço: o perfil cognitivo do leitor imersivo. São Paulo: Editora Paulus, 2004.

SAVI. R; ULBRICHT, V. R. Jogos digitais educacionais: benefícios e desafios. Revista Novas Tecnologias na Educação. v. 6, n. 2, p. 1-10. 2008. Disponível em: <www.seer.ufrgs.br/renote/article/download/\%2014405/8310>. Acesso em: 15 fev. 2016.

SCOLARI, A. T.; BERNARDI, G.; CORDENONSI, A. Z. O Desenvolvimento do Raciocínio Lógico através de Objetos, de Aprendizagem, 2007. Disponível em: <http://www.cinted.ufrgs.br/ciclo10/artigos/4eGiliane.pdf>. Acesso em: 23 nov 2010.

SILVA, T. R.; LIMA, R. W.; MESQUITA, H. H. O.; MARQUES, C. K. M. O uso de ferramentas pedagógicas no desenvolvimento de Objetos de Aprendizagem. Revista de Informática Aplicada, v. 9, n. 1, 2013.

SILVA-FILHO, A. M. O papel da tecnologia da informação e comunicação na melhoria do processo de ensino e aprendizagem. Revista Espaço Acadêmico, n. 74, ano VII, 2007.

SANTOS, E. de F. G.; CRUZ, D. M. e PAZZETTO, V. T. Ambiente Educacional Rico em Tecnologia: A Busca do Sentido. Associação Brasileira de Educação a Distância. Disponível em:

<http://www.abed.org.br/site/pt/midiateca/textos_ead/634/ambiente_educacio nal_rico_em_tecnologia_a_busca_do_sentido_>. Acesso em: 28 ago. 2016.

SUZUKI, J. T. F.; RAMPAZZO, S. R. R. Tecnologias em Educação. São Paulo: Pearson Education do Brasil, 2009.

TAVARES, R.; OLIVEIRA, D.; LARANGEIRO, D.; ALMEIDA, M. Universal Design for Learning: potencial de aplicação no Ensino Superior com alunos com NEE e por recurso a tecnologias mobile. Revista EFT: Educação, Formação \& Tecnologia, n. 8, 2015.

VALCÁRCEL, A. G.; REPISO, M. Tecnología Educativa: implicaciones educativas del desarrollo tecnológico. Madrid: Editora La Muralla, 2003. 
VAlENTE, J. A. Prefácio. In: BACICH, L.; NETO, A. T.; TREVISANI, F. M. (Orgs.) Ensino Híbrido: personalização e tecnologia na educação. Porto Alegre: Penso, 2015. p. 13-20.

VICKERY, A. Criando uma cultura da indagação. In: VICKERY, A. et al. Aprendizagem ativa nos anos iniciais do ensino fundamental. Porto Alegre: Penso, 2016. p. 43-66.

WELLER, M.; PEGLER, C.; MASON, R. Putting the pieces together: What working with learning objects means for the educator, 2003.

WILEY, D. The instructional use of learning objects. On-line version. Disponível em: <http://reusability.org/read/>. 2000. Acesso em: 20/02/2007.

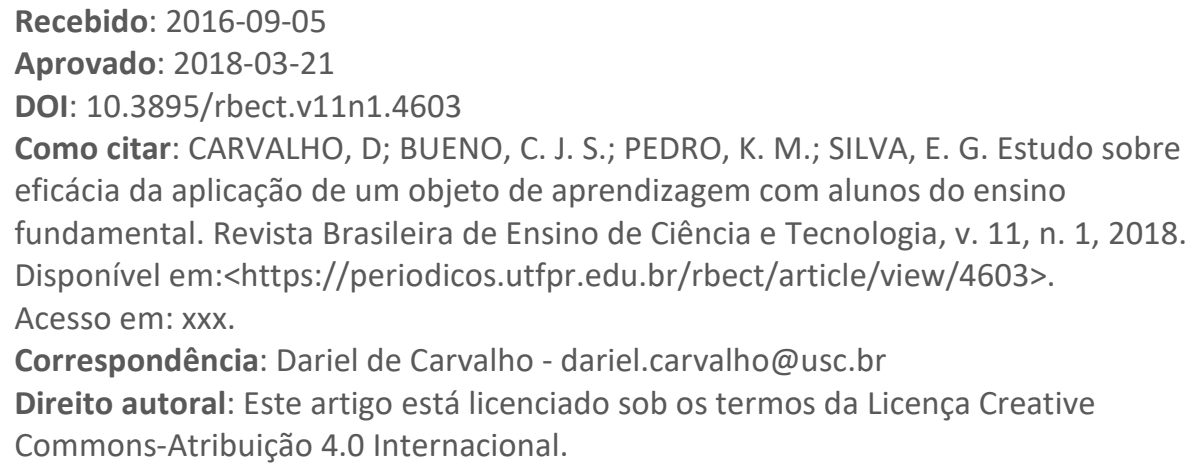

